\title{
GESTÃO DE PESSOAS NO PET ELÉTRICA: AMBIENTE HARMÔNICO, DE ACOLHIMENTO E DESENVOLVIMENTO DE COMPETÊNCIAS SOCIOEMOCIONAIS NA FORMAÇÃO DE ENGENHEIROS
}

DOI: 10.37702/2175-957X.COBENGE.2021.3602

Esteban Vicente Aguilar Bojorge - esteban.aguilar@engenharia.ufjf.br Universidade Federal de Juiz de Fora

Rua Severino Meireles 325

36025-040 - Juiz de Fora - MG

Juliana Quinelato - juliana.quinelato@engenharia.ufjf.br

Universidade Federal de Juiz de Fora

Rua Hortogamine dos Reis 159

36021-290 - Juiz de Fora - MG

Kássia Cristina Carvalho Santos - kassia.carvalho@engenharia.ufjf.br

Universidade Federal de Juiz de Fora

Rua G 320

27570-000 - Porto Real - RJ

Matheus Taninho Reinh - taninho.reinh@engenharia.ufjf.br

Universidade Federal de Juiz de Fora

Rua Maria Luiza Tostes 38

36080-490 - Juiz de Fora - MG

Resumo: Atualmente, as dinâmicas das relações interpessoais em um ambiente de trabalho, buscam cada vez mais mecanismos e práticas que possibilitem uma maior valorização dos colaboradores, contribuindo dessa forma para a evolução e crescimento de uma organização. Neste contexto, o PET Elétrica, através da implementação de um projeto de Gestão de Pessoas, entende a necessidade de exploração de novas competências socioemocionais, que geram impacto significativo na atuação de um Engenheiro em sua atividade profissional. Apesar do crescimento da equipe em áreas correlatas à engenharia, identificou-se que havia espaço para a realização de um estudo aprofundado sobre a gestão estratégica de pessoas, envolvendo avaliação, administração e orientação das 
ações comportamentais dos membros do grupo. Através de análises internas e de acompanhamentos das atividades dos petianos, foi possível observar que a criação do projeto promoveu uma maior integração e alinhamento dos membros com os objetivos e metas do PET Elétrica, além de viabilizar um acolhimento integral aos participantes do grupo propiciando, assim, um ambiente harmônico e saudável. Portanto, o presente estudo, reforça a importância de avaliar, conhecer e valorizar o desenvolvimento dos petianos, possibilitando desta forma o aprimoramento dos valores que constituem a base do Programa de Educação Tutorial.

Palavras-chave: Gestão de Pessoas; Competências Socioemocionais; Programa de Educação Tutorial 


\section{GESTÃO DE PESSOAS NO PET ELÉTRICA: AMBIENTE HARMÔNICO, DE ACOLHIMENTO E DESENVOLVIMENTO DE COMPETÊNCIAS SOCIOEMOCIONAIS NA FORMAÇÃO DE ENGENHEIROS}

\section{INTRODUÇÃO}

Em um mundo corporativo extremamente competitivo, um engenheiro que tenha apenas habilidades técnicas adquiridas ao longo do curso universitário, não se diferencia em um ambiente de trabalho que busca, cada vez mais, profissionais que possuam um desenvolvimento consolidado de suas competências socioemocionais, 0 que possibilita uma melhoria significativa em suas relações interpessoais. Desta forma, a reestruturação e a renovação do ensino de engenharia vêm sendo discutida no âmbito do Programa de Educação Tutorial do curso de Engenharia Elétrica (PET Elétrica) da Universidade Federal de Juiz de Fora (UFJF), com o objetivo garantir a formação integral do aluno e aperfeiçoar a graduação.

Desde sua criação, em 1991, o PET Elétrica desenvolve projetos pautados na tríade da educação: ensino, pesquisa e extensão, seguindo as normas gerais descritas no Manual de Orientações Básicas (MOB, 2006) do programa. Apesar da natureza de cunho técnico do curso, as atividades do grupo buscam também desenvolver em seus membros, os petianos, competências e habilidades que proporcionem oportunidades de pesquisa sobre temas não relacionados somente à área de atuação de um engenheiro eletricista. Neste contexto, apesar do sucesso do programa, no ano de 2020, a equipe notou que havia margem para melhoria em questões envolvendo a administração comportamental dos membros, abrindo caminho para um estudo que levaria, posteriormente, a criação de uma Gestão de Pessoas.

Faz-se necessária a ressalva quanto ao uso do termo Recursos Humanos, que está em desuso. A Teoria das Relações Humanas (CHIAVENATO, 2003), impulsionada pelo cenário pós Grande Depressão, passa a tratar essas relações de acordo com a premissa de que o humano não pode ser reduzido a alguém cujo comportamento é simples e mecânico e de que todos possuem necessidades de segurança, afeto, aprovação e prestígio.

Por muitos anos as organizações não enxergavam no capital humano o essencial para seu crescimento, entretanto essa perspectiva mudou. Atualmente o sucesso de um grupo está diretamente ligado ao talento, habilidades e competências dos membros. A motivação constante e a qualidade de vida do colaborador fazem extrema diferença nos resultados de uma organização (FERNANDES, 1996). Segundo Chiavenato, a gestão de pessoas apresenta um ponto de vista sobre ocupação e colaborador, que prevê e simultaneamente, orienta seus atos. Pode-se concluir que uma gestão adequada propicia a criação de vínculo forte e decisivo entre as técnicas e as pessoas.

Neste contexto, o PET Elétrica propôs implementar atividades que fossem intrinsecamente relacionadas aos seis processos (CHIAVENATO, 1999) da Gestão de Pessoas: agregar, aplicar, recompensar, desenvolver, manter e monitorar pessoas.

Assim, este trabalho tem como fundamento discutir acerca da implementação de um conjunto de práticas que envolvem técnicas de motivação, retenção e capacitação dos membros, e que possibilitam a evolução e o crescimento do grupo. A gestão estratégica de pessoas atende questões até então desprezadas, mas que atualmente permitem ao PET Elétrica garantir um ambiente de trabalho saudável, que propicia meios para a realização de seus objetivos. 


\section{PROJETO}

Anteriormente, o PET Elétrica contava com diferentes atividades - até então não vinculadas - e realidades que motivaram a criação do projeto Gestão de Pessoas. A primeira das atividades em questão é o Planejamento Estratégico (PE), que se relaciona com os objetivos de longo prazo e com estratégias e ações para alcançá-los (REBOUÇAS, 2001), sendo responsável por definir a missão, visão e valores, além das metas da equipe, traçando o plano de ação correspondente. Em um primeiro momento, após a aplicação do Planejamento Estratégico, a missão, visão e valores do grupo estavam em fase de maturação e as metas não estavam inteiramente difundidas na cultura organizacional do programa, e verificava-se algumas dificuldades na organização e na condução da equipe ao encontro das metas estabelecidas.

Um PE não consolidado pode acabar refletindo negativamente na qualidade da segunda atividade: o Processo Seletivo (PS). Torna-se complexa a tarefa de selecionar novos membros num ambiente em que não há objetivos claramente definidos. Sendo assim, é necessário conhecer o perfil e as metas do grupo, para que o PS possa realizar o recrutamento dos candidatos mais alinhados às definições estabelecidas pelo PE. Com isso, busca-se que os candidatos tenham conhecimento acerca do Programa de Educação Tutorial e suas normas, e do grupo PET Elétrica - os projetos que desenvolve, sua missão, visão e valores. Isto visa que, ao ingressar no grupo, os novos petianos estejam adaptados à realidade de trabalho do grupo, conheçam a metodologia de ensino aprendizagem adotada e os processos avaliativos implantados, tornando mais fácil sua adaptação no ambiente do grupo e nos projetos que irão atuar.

A terceira atividade é o Rito de Desligamento, que ocorre quando um petiano é desligado do grupo. O objetivo deste é buscar entender os motivos da saída do membro e como isso poderia ser evitado, além do impacto em seu aproveitamento acadêmico. Por fim, são colhidos relatos dos demais petianos acerca da sua participação na equipe que são entregues na forma de uma carta de despedida.

As outras atividades são realizadas por uma Comissão de Avaliação (CA), que tem como objetivo zelar pelo cumprimento dos deveres dos petianos, pelo bom andamento dos projetos e pelo acompanhamento individualizado dos membros, além do incentivo a boas práticas com um sistema de pontuação idealizado para incentivar a equipe por meio de prêmios. Outra de suas atribuições é realizar a autoavaliação, com o Instrumento de Avaliação elaborado pela Comissão Executiva Nacional dos Grupos PET (CENAPET), entidade que congrega todos os petianos do Brasil. Este instrumento se propõe a subsidiar a avaliação das atividades dos grupos PET, com o objetivo de identificar os seus pontos fortes e pontos fracos, promover as boas práticas, buscar o constante aperfeiçoamento e atender aos objetivos e às diretrizes nacionais do Programa (CENAPET, 2015). As notas da autoavaliação do instrumento variam de zero a cinco. 
Figura 1 - Fluxograma das atribuições da Gestão de

Pessoas.

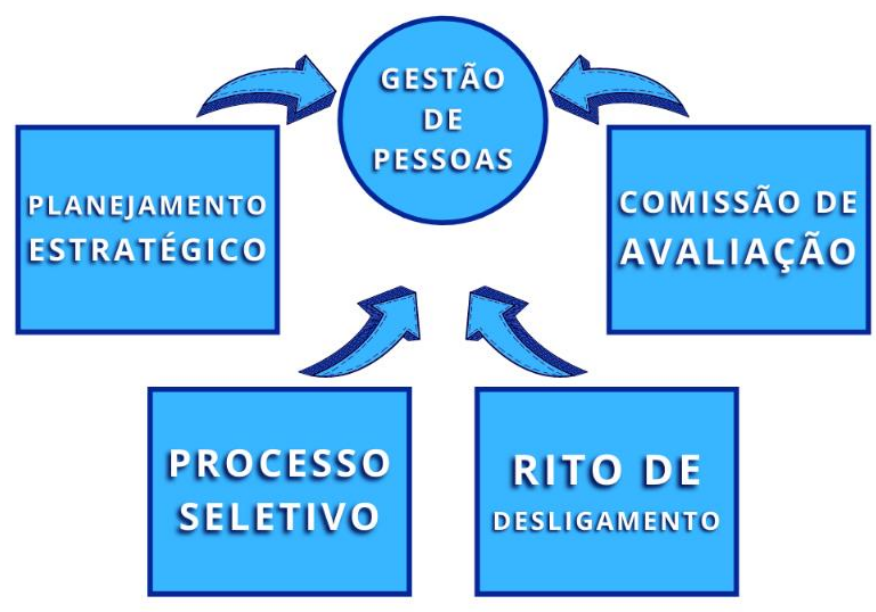

A proposta inicial foi unificar tais atividades em um único projeto de Gestão de Pessoas, conforme Figura 1, de forma a tornar a comunicação entre essas mais eficaz. Apesar da gestão de pessoas requerer o conhecimento específico de outra área, é importante que haja espaço para tratar e promover a qualidade de vida no ambiente de trabalho. Dessa forma, foram indicados para participar da primeira equipe deste projeto os petianos que estavam a mais tempo no PET Elétrica ou que demonstravam interesse nesta área.

\section{METODOLOGIA}

Iniciada a Gestão de Pessoas (GP) do PET Elétrica, o primeiro passo foi buscar a capacitação daqueles que seriam os responsáveis por aplicar as alterações na dinâmica de atividades e rotina do grupo no que tange às áreas da GP. Por não ser a área de domínio do curso de Engenharia Elétrica, se mostrou necessária a aplicação da metodologia de aprendizagem ativa, que corresponde a métodos onde o estudante é envolvido ativamente no processo de construção do seu conhecimento (GOMES, 2015), conhecida como Aprendizagem Baseada em Projetos (do inglês Project Based Learning) (PjBL), na qual a própria equipe busca o conhecimento do problema, soluções a serem implementadas dentro do grupo e tomadas de decisão (SRIDHARA, 2015) (FALAND \& FRENAY, 2006). Tal busca resultou em trocas de experiências com outros grupos PET e com profissionais do âmbito da psicologia e demais áreas afins.

Além da capacitação, foi definido que a equipe se tornaria responsável por aprimorar e promover algumas atividades que já eram realizadas pelo grupo, como as avaliações internas semestrais, o Planejamento Estratégico, o Rito de Desligamento, o Processo Seletivo, e as atividades da Comissão de Avaliação. Entretanto, a Gestão de Pessoas não se limitou a isso, e trouxe novas atividades para o PET Elétrica, entre elas a Pesquisa de Clima Organizacional e os formulários de autoconhecimento.

O principal objetivo da GP é criar um ambiente de trabalho agradável, aumentando a motivação dos petianos e por consequência a produtividade de todo o grupo. Para isso, era necessário conhecer o perfil do grupo, que foi traçado através de formulários de análise de comportamentos. Outra abordagem necessária para melhorar as avaliações internas e dos valores do PET Elétrica se deu por meio de capacitações ministradas ao restante do 
grupo, sobre como aprimorar o senso crítico e como realizar e receber feedbacks de maneira apropriada.

A Pesquisa de Clima Organizacional (PCO), que consiste na percepção do colaborador quanto ao apoio organizacional (EISENBERGER et al., 1986), a estrutura do grupo (PAYNE \& PUGH, 1976) e ao comportamento das pessoas na instituição (WOODMAN \& KING, 1978), levando em conta aspectos como liderança, satisfação, motivação, entre outros (OLIVEIRA, 1996), feita de três em três meses, é importante para identificar possíveis problemas que afetem o ambiente de trabalho, além de gerar maior engajamento da equipe para com o programa e aos demais petianos.

Quanto ao Processo Seletivo (PS), tornou-se responsabilidade direta da Gestão de Pessoas elaborar o onboarding, que é a etapa de imersão do novos petianos ao grupo do PET Elétrica, além da criação de um sistema de apadrinhamento, no qual é designado um padrinho responsável por familiarizar e inserir o novato na cultura organizacional da equipe. Uma estratégia utilizada para outorgar o Rito de Desligamento foi realizá-lo, sempre que possível, ao final do Processo Seletivo, simultaneamente à recepção dos novos membros à equipe, com o intuito de criar, desde o início, o sentimento de responsabilidade e a imersão na cultura do grupo aos novos petianos.

Em conjunto com o projeto de Comunicação e Marketing do PET Elétrica, foi utilizada a ferramenta "melhores amigos" do Instagram para incentivar feedbacks puramente positivos, bem como o acompanhamento das metas do Planejamento Estratégico, visando informar sobre o andamento das metas e a manter a motivação do grupo constantemente elevada.

Todas as atividades propostas ajudaram o PET Elétrica a criar um ambiente harmonioso de trabalho, mas o relacionamento humano foi de longe a atividade mais impactante para o grupo. A realidade atual do PET Elétrica é de 24 membros, sendo 18 oficiais, 5 voluntários extraoficiais e 1 tutor. A composição da GP conta com 7 petianos oficiais. A proposta é que cada membro da Gestão de Pessoas se responsabilize pelo acompanhamento individual de três petianos, em média, e que esse ocorra mensalmente. Nessas reuniões são discutidas questões como a motivação, gestão de conflitos e dificuldades na execução das atividades. No entanto, apesar dessa estrutura, é importante que todas as partes se sintam livres para conduzir os acompanhamentos da forma que melhor atenda a cada realidade, com o intuito de não apenas promover o conhecimento mútuo destes, mas também abrir um canal de comunicação para questões pessoais.

O desempenho das atividades desenvolvidas foi avaliado mediante pesquisas entre os integrantes do PET Elétrica e os resultados e discussões são apresentados na seguinte seção.

\section{$4 \quad$ RESULTADOS}

De acordo com os objetivos estabelecidos e a metodologia empregada em sua execução, era esperado que a Gestão de Pessoas tivesse impacto significativo e positivo nas relações humanas do PET Elétrica.

O resultado gerado pelo projeto "Gestão de Pessoas" foi avaliado por meio de diferentes indicadores: competências socioemocionais e técnicas desenvolvidas por cada membro do projeto e o impacto gerado no grupo PET Elétrica. As notas variam de zero a cinco em todos os formulários. 


\subsection{Para a equipe de Gestão de Pessoas}

Através de atividades avaliativas internas, percebeu-se que competências técnicas sobre gestão de pessoas foram adquiridas. Isso se deu por meio de pesquisas, minicursos e parcerias realizadas. Dentre esses conhecimentos se destacam a criação de um Planejamento Estratégico, a reformulação do Processo Seletivo, o aperfeiçoamento do Rito de Desligamento e dos processos avaliativos, bem como o acompanhamento individual utilizando conceitos de gestão comportamental, feedback e clima organizacional.

Foi possível constatar, através de autoavaliações realizadas com a equipe do projeto, que consistia originalmente de oito membros, o desenvolvimento de várias habilidades e competências, destacando-se a capacidade de avaliação, autoavaliação e senso crítico, como é possível observar na Figura 2, que traz as autoavaliações dos membros da Gestão de Pessoas acerca das competências que adquiriram participando do projeto.

Figura 2 - Gráfico das respostas dos membros da Gestão de Pessoas.

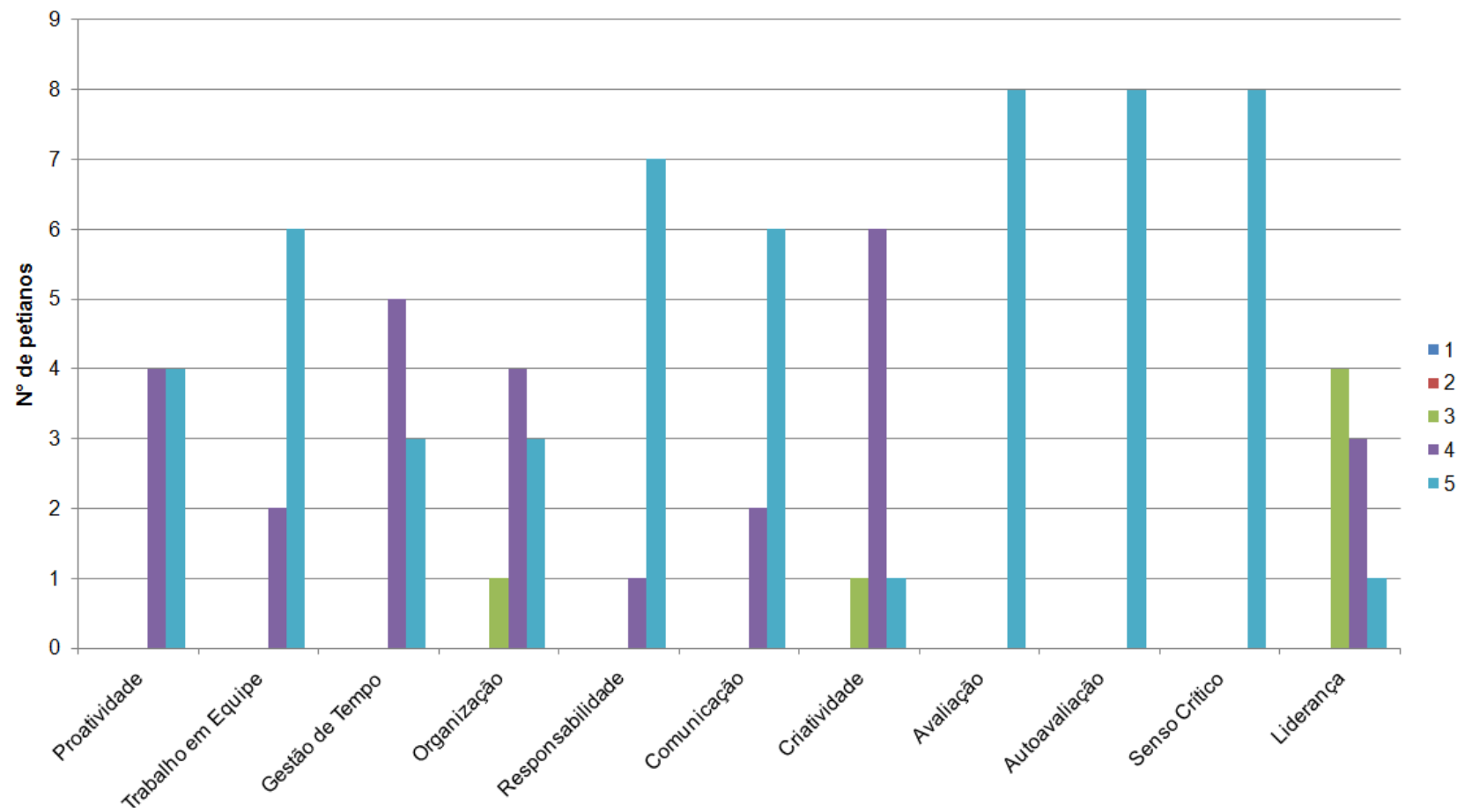

\subsection{Para a equipe do PET Elétrica}

Na primeira atividade, Planejamento Estratégico (PE), foi perceptível uma melhora na identificação das pessoas com o grupo e uma melhor condução dos projetos por parte dos coordenadores e suas equipes, o que contribuiu para alcançar as metas e cumprir a missão e a visão do grupo.

No PS do segundo semestre de 2019, 11 novos petianos foram incorporados e muitos relataram dificuldade na adaptação a este novo ambiente, muitas vezes não conhecendo a totalidade de projetos do PET Elétrica e em quais poderiam estar atuando. Contudo, quando realizado no primeiro semestre de 2021, momento em que a Gestão de Pessoas já estava consolidada, foi possível identificar candidatos mais bem alinhados ao PE, quando comparados aos candidatos de processos anteriores.

Um detalhe importante foi a percepção dos oito recém aprovados quanto ao ambiente de trabalho, como pode-se observar na Figura 3, em contraste com a percepção 
dos quinze petianos já presentes no grupo antes do último processo seletivo, como notase na Figura 4. Essas figuras trazem gráficos com as autoavaliações dos petianos sobre a percepção do ambiente de trabalho. Considerando as notas quatro e cinco como uma avaliação satisfatória, é possível perceber uma melhora de $66 \%$ em relação a facilidade de inserção no grupo, $61 \%$ referente a adaptação às atividades, $36 \%$ no conhecimento da estrutura e funcionamento do PET e por fim, $68 \%$ no sentimento de pertencimento ao grupo.

Figura 3 - Gráfico das respostas dos petianos incorporados no primeiro semestre de 2021.

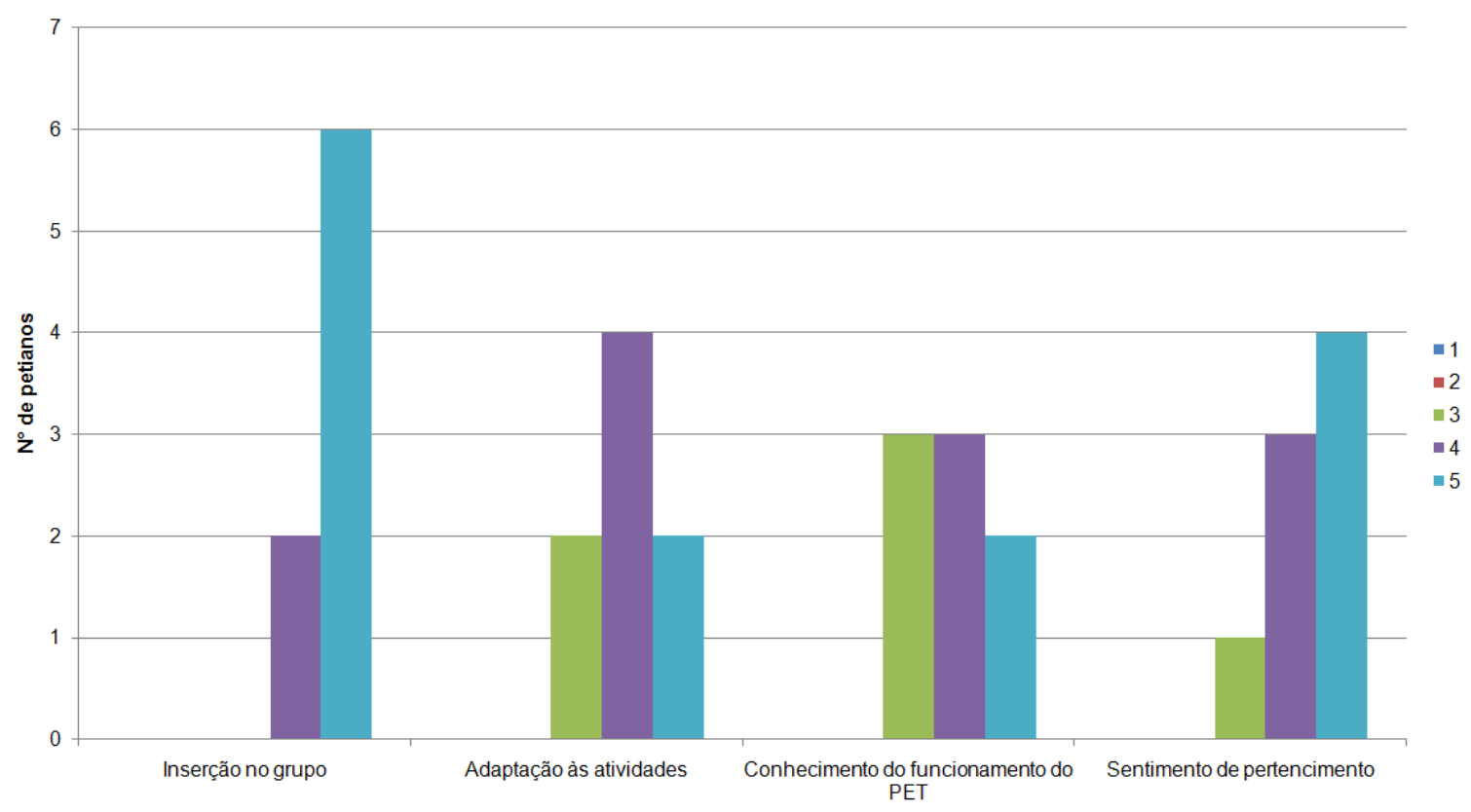

Figura 4 - Gráfico das respostas dos petianos anteriores ao processo seletivo do primeiro semestre de 2021.

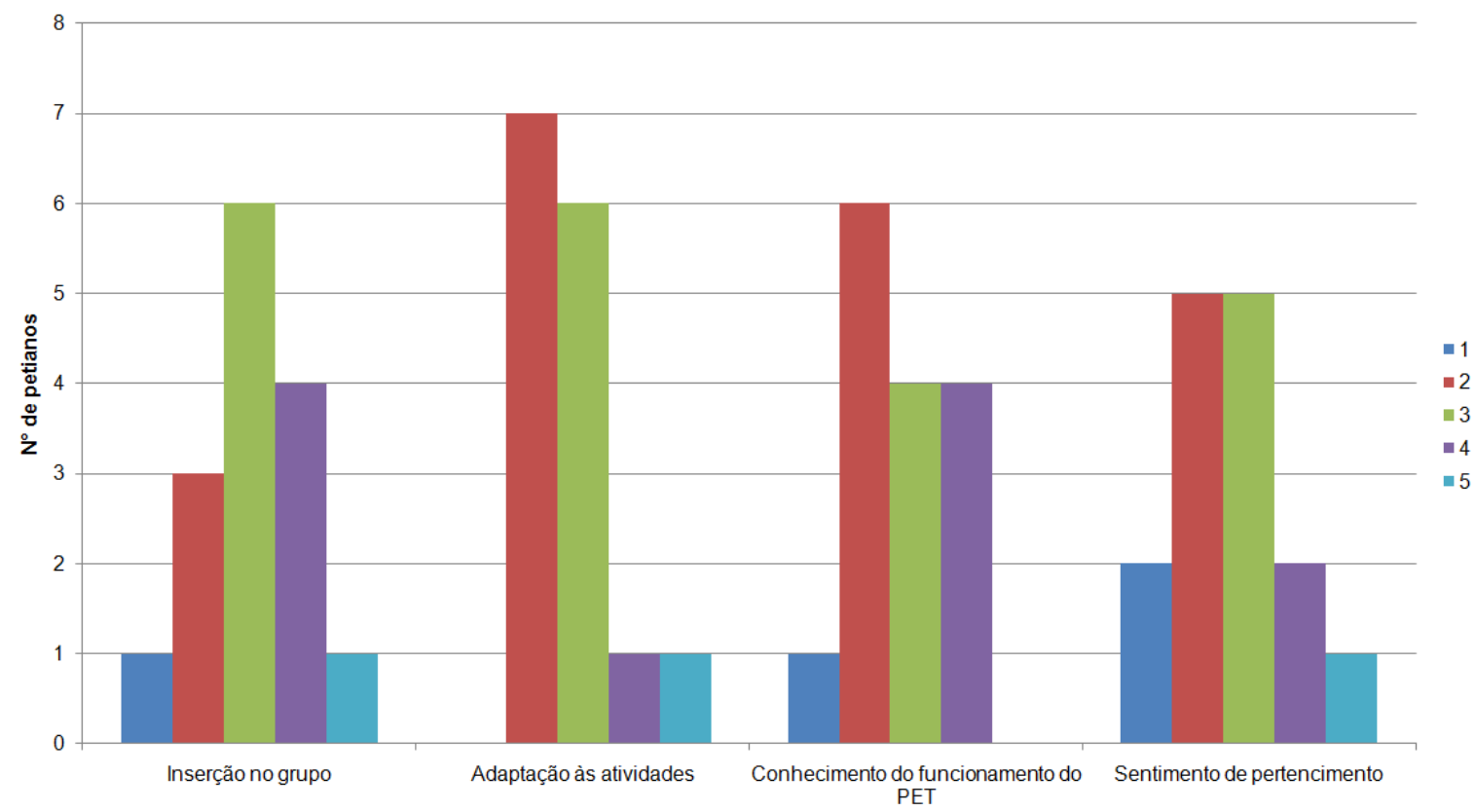


Nas atividades referentes à Comissão de Avaliação, a GP passou a realizar o acompanhamento dos deveres do petiano, o bom andamento dos projetos e 0 acompanhamento individual, discutindo questões como motivação, gestão de conflitos e dificuldades na execução das atividades, a fim de promover um espaço para tratar da qualidade de vida e de trabalho.

De acordo com o instrumento de avaliação elaborado pela CENAPET, que tem como objetivo buscar um constante aperfeiçoamento do programa, a Gestão de Pessoas pôde influenciar diretamente nos resultados da avaliação dos seguintes macro eixos: Planejamento e Avaliação, Desenvolvimento Institucional e Políticas de Gestão.

Com a implementação de uma gestão estratégica de pessoas, foi possível identificar os principais elementos do processo avaliativo da Instituição de Ensino Superior em relação à organização do grupo PET Elétrica, que teve como intervenção direta a execução do Planejamento Estratégico. Neste quesito o grupo obteve nota 4,17 na média final do macro eixo Planejamento e Avaliação, como pode-se observar na Figura 5. No macro eixo Desenvolvimento Institucional o grupo obteve média final de 2,83. Nesta avaliação identificou-se a coerência existente entre o planejamento e as ações do grupo nas diferentes vertentes de sua atuação acadêmica, baseada na tríade de ensino, pesquisa e extensão.

Em relação às Políticas de Gestão, eixo em que o projeto obteve maior atuação, as ações da Gestão de Pessoas foram concentradas em alcançar melhores resultados, com enfoque na coerência entre as atividades dos membros e princípios reguladores do programa PET. Além disso, foram avaliados a relação entre a aplicação de recursos, o planejamento anual e a política de acompanhamento dos resultados. Neste quesito, o PET Elétrica obteve nota média final de 4,28.

Figura 5 - Gráfico da autoavaliação do PET Elétrica no instrumento da CENAPET.

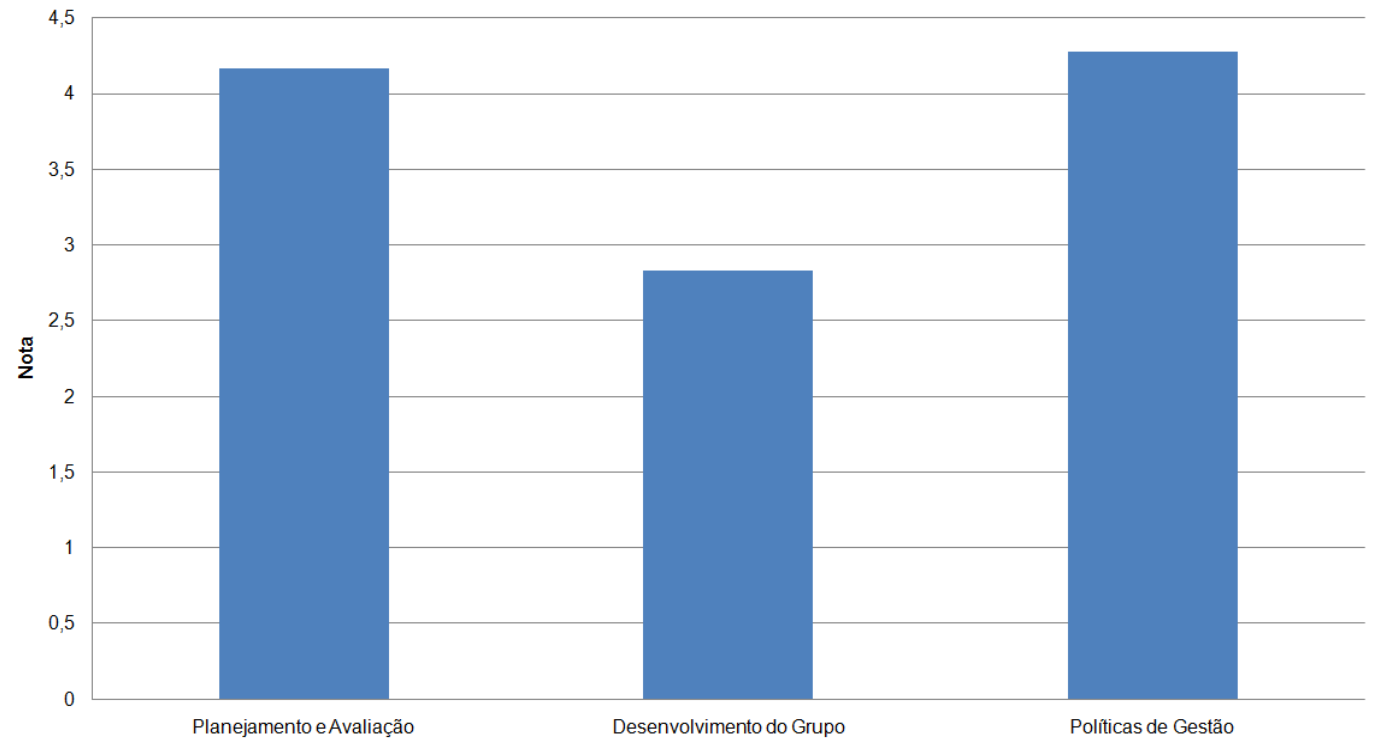

Como resumo geral, em pesquisa interna, foi possível perceber mudanças de fatores com a implementação da Gestão de Pessoas, destacando-se a integração, a realização de feedbacks e a aceitação de críticas, como pode-se observar na Figura 6, que traz as respostas dos membros do PET sobre as competências adquiridas em forma de gráfico. 
Figura 6 - Gráfico das respostas dos membros do PET Elétrica.

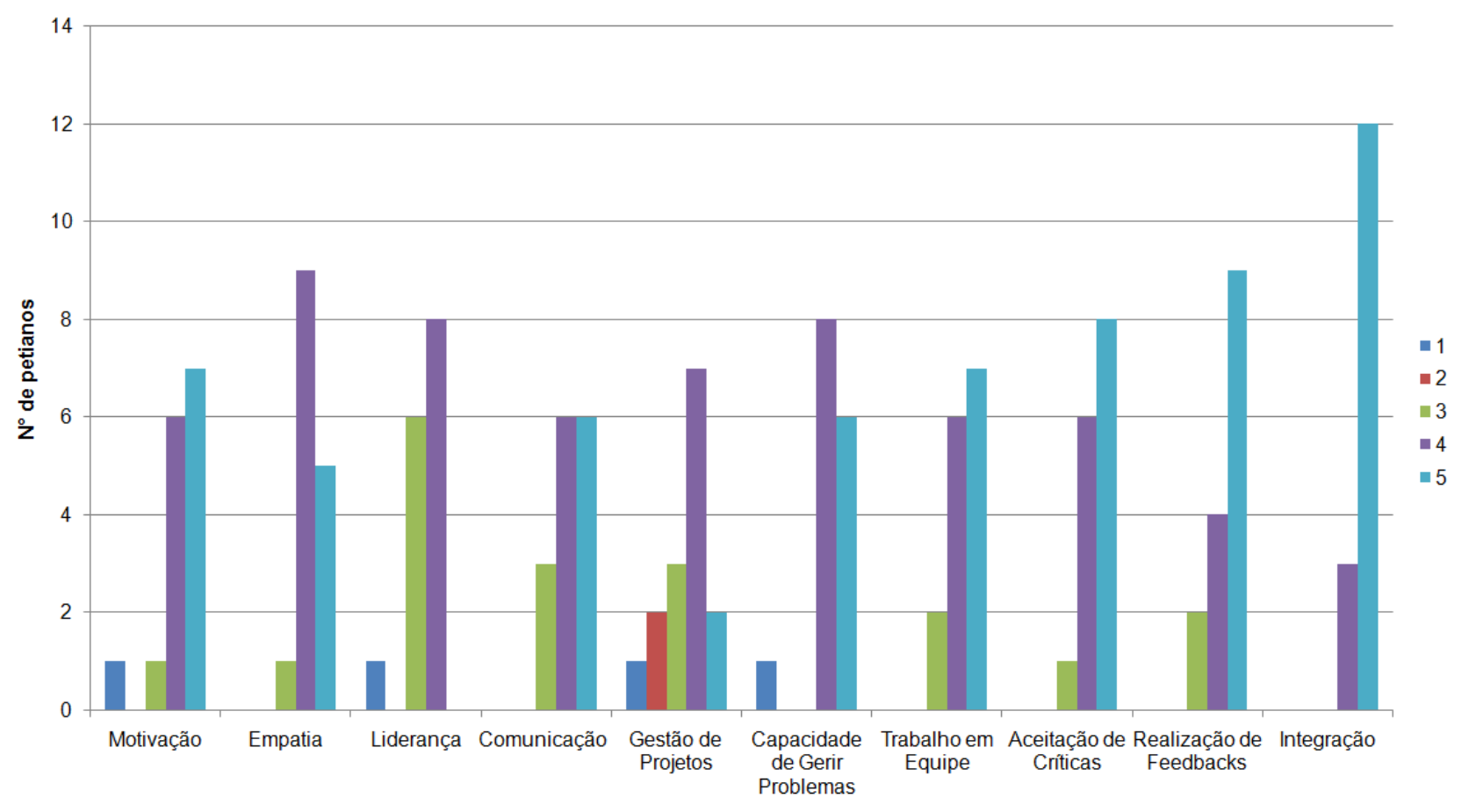

\section{Considerações Finais}

O PET Elétrica, através dos projetos realizados utilizando a metodologia de ensino aprendizagem $\mathrm{PjBL}$, procura desenvolver ou reforçar as competências necessárias ao desenvolvimento profissional do engenheiro (técnicas e socioemocionais), bem como busca oportunizar que o petiano tenha uma formação integral (engenheiro cidadão). Portanto, atua na promoção de melhorias constantes nos cursos de graduação, integrando o petiano ao seu contexto socioeconômico, por meio de atividades de extensão, além dos contextos científico e cultural. De acordo as Diretrizes Curriculares Nacionais:

[...] chama-se a atenção para a contribuição positiva das empresas juniores e grupos especiais (como o PET-Capes) [...] Iniciativas como essas devem ser especialmente consideradas no projeto do curso e na sua estrutura, evidentemente que preservando a autonomia das atividades/empresas em termos de funcionamento e atuação. (BRASIL, 2019).

A realidade corporativa na qual estamos inseridos exige que 0 engenheiro aplique conhecimentos empíricos, técnicos e científicos à criação e à modificação de mecanismos, estruturas, produtos e processos. Em suma, o profissional deve atuar com transformações não apenas de cunho técnico, mas também que impactam a dimensão humana, apresentando um perfil oriundo de uma formação generalista, humanista, crítica e reflexiva.

Dessa forma, cabe ao engenheiro estar atento a questões às quais nunca lhe fizeram respeito. No entanto, os currículos na maioria dos cursos de graduação em engenharia não foram concebidos de modo a permitir, viabilizar ou incentivar que os discentes possam desenvolver tais competências socioemocionais. Com isso, a filosofia do Programa de Educação Tutorial é um importante motor ao proporcionar a melhorar a qualidade 
acadêmica dos cursos de graduação apoiados, como referido no Manuel de Orientações Básicas do Programa de Educação Tutorial - PET:

Garantir aos alunos do curso a oportunidade de vivenciar experiências não presentes em estruturas curriculares convencionais, visando a sua formação integral e favorecendo a formação acadêmica, tanto para a integração no mercado profissional quanto para o desenvolvimento de estudos em programas de pós-graduação. (BRASIL, 2006).

Nesse sentido, o trabalho desenvolvido pela Gestão de Pessoas do PET Elétrica tomou para si a responsabilidade de gerar um ambiente de trabalho harmonioso. Conhecer melhor a realidade de cada petiano e reforçar as competências de cada um, possibilitou que desligamentos precoces fossem evitados, tornou possível a identificação de pontos de melhoria e facilitou o desenvolvimento pessoal por meio de capacitações acerca dos valores que poderiam ser aprimorados. O trabalho em equipe também se tornou mais eficaz, fruto da melhor comunicação entre todas as partes.

Os petianos que participam ativamente das atividades aumentaram sua capacidade de gerir problemas e lidar com o ambiente de trabalho em equipe, tornando o grupo aberto a críticas, sugestões e feedbacks. Ao proporcionar a integração da equipe de forma planejada, a produtividade do PET Elétrica como um todo foi elevada.

Por fim, percebe-se que a aplicação de uma Gestão de Pessoas a outros alunos do curso, por meio de acompanhamento e de acolhimento do corpo docente, podem ser proveitosa, formando engenheiros em um ambiente harmônico, com suas competências socioemocionais reforçadas e preparados para os desafios atuais do mercado de trabalho que, cada vez mais, exige profissionais com percepções holísticas das suas funções. 


\section{Agradecimentos}

Ao Programa de Educação Tutorial PET/MEC e à Faculdade de Engenharia da Universidade Federal de Juiz de Fora pelo suporte para realização deste trabalho.

\section{REFERÊNCIAS}

BRASIL. Ministério da Educação; Conselho Nacional de Educação. Diretrizes Curriculares Nacionais do Curso de Graduação em Engenharia, 2019. Disponível em: http://portal.mec.gov.br/index.php?option=com_docman\&view=download\&alias=109871 pces001-19-1\&category_slug=marco-2019-pdf\&Itemid=30192. Acesso em: 19 abr. 2021. BRASIL. Ministério da educação; Secretaria de Educação Superior. Programa de Educação Tutorial - PET - Manual de Orientações Básicas, 2006. Disponível em: http://portal.mec.gov.br/index.php?option=com_docman\&view=download\&alias=338manualorientabasicas\&category_slug=pet-programa-de-educacao-tutorial\&ltemid=30192. Acesso em: 19 abr. 2021.

CHIAVENATO, Idalberto. Gestão de Pessoas: o novo papel dos recursos humanos nas organizações. 6 ed. Rio de Janeiro: Editora Campus S.A, 1999.

CHIAVENATO, Idalberto. Introdução à Teoria Geral da Administração. 7 ed. Rio de Janeiro: Elsevier, 2003.

COMISSÃO EXECUTIVA NACIONAL DO PROGRAMA DE EDUCAÇÃO TUTORIAL (CENAPET). Minuta de Instrumento de Avaliação PET elaborada pela Comissão de Avaliação, 2015. Disponível em https://cenapet.org/orientacoes. Acesso em 19 de abril de 2021.

EISENBERGER, Robert et al. Perceived organizational support. Journal of Applied Psychology, v. 71, n. 3, p. 500, 1986.

FALAND, B.; FRENAY, M. Problem and Project Based Learning in High Education: Impact. Issues, and Challenges, Louvain-la-Neuve: Presses Universitaires de Louvain, 2006. FERNANDES, Eda Conte. Qualidade de vida no trabalho: como medir para melhorar. Salvador: Casa da Qualidade, 1996.

GOMES, Francisco José. Reflexões sobre a prática tutorial na educação em engenharia. 2015. 200 f. Tese (Professor Titular) - Faculdade de Engenharia, Universidade Federal de Juiz de Fora, Juiz de Fora, 2015.

OLIVEIRA, W. M. Perfil analítico-descritivo da pesquisa sobre clima organizacional em instituições de ensino superior: 1970-1995. 1996. Tese (Doutorado) - Faculdade de Economia, Administração e Contabilidade, Universidade de São Paulo, São Paulo, 1996. PAYNE, Roy; PUGH, Derek S. Organizational structure and climate: Handbook of industrial and organizational psychology. Chicago: Rand McNally College Publishing Company, 1976.

REBOUÇAS, Djalma de Pinho. Planejamento Estratégico: Conceitos Metodologia Práticas. São Paulo: Atlas, 2001.

SRIDHARA, B. S. Teaching Engineering Fundamentals with a Project-Based Learning. In: Proceedings of the 2005 American Society for Engineering Education Annual Conference \& Exposition Copyright. 2005.

WOODMAN, R. W. \& KING, D. C. Organizational climate: science as folklore. In Academy of Management Review. Vol. 3, p. 816-26, 1978. 


\title{
PEOPLE MANAGEMENT IN PET ELÉTRICA: HARMONIC WORKSPACE, RECEPTIONING AND DEVELOPING SOCIO-EMOTIONAL SKILLS IN QUALIFYING ENGINEERS
}

\begin{abstract}
Currently, the dynamics of interpersonal relationships in work environments, increasingly seek mechanisms and practices that enable greater recognition of employees, thus contributing to the evolution and growth of an organization. In this context, PET Elétrica, through the implementation of a People Management project, understands the need to explore new socio-emotional skills, which generate a significant impact on the performance of an Engineer in his professional activity. Despite the team's growth in areas related to engineering, it was identified that there was space for an in-depth study on the strategic management of people, involving assessment, administration and guidance of the behavioral actions of the group members. Through internal analyzes and supporting of the group's activities, it was possible to observe that the creation of the project promoted a greater integration and alignment of the members with the objectives and goals of PET Elétrica, in addition to enabling a full reception to the group participants, thus providing, a harmonious and healthy environment. Therefore, this paper reinforces the importance of evaluating, knowing and valuing the development of each member, thus enabling the improvement of the values that form the basis of the Tutorial Education Program.
\end{abstract}

Keywords: People Management. Socio-emotional Skills. Programa de Educação Tutorial. 